\title{
Etiología de las neumopatías agudas del lactante
}

\author{
Dr. Arturo Gallo B., Dr. Rubén Puentes R., Dra. Sonia Kunstmann F., \\ Kin. Elisabeth Arenas G. y T. Méd. Ingrid Riedel K. ${ }^{1}$

\section{The ethiology of acute pneumonia in infants}

\begin{abstract}
Bacteriological studies were done in blood, traqueal secretions and fluid ob1ained by lung puncture from 24 infants with Pneumonia,

Lung puncture gave positive results in 4 of them (I $7 \%$, in 3 to different types of staphilococcus and in 1 to a combination of Streptococcus pneumoniae and viridans. Blood cultures were also positjve in 4 infants (2 Staphilococcus, 1 Citrobacter aerogenes and 1 Streptococcus pneumoniae). There was only one patient in whom the same organism was isolated from lung and blood Bacteriae were isolated from the traqueal secretions of $78 \%(14 / 18)$ of the infants studied, but the organisms were those commonly cultured from the upper respiratory tract.

Neither blood sedimentation rates nor blood white cell counts correlated with the isolation of bacterias from lung and blood. The only exception was a leucocite count higher thar 12.000 , present in a significant proportion of patients with positive cultures.

Thete wore no complications from lung puncture.

In spite of the low proportion of positive blood or lung aspirate cultures considered separately, there were $7 / 24$ ( $29 \%$ patjents with either of them positive. These results seem to justify these procedures in some infants with infectious lung disease, specially in those who do not respond to first line antibiotics and in hospitals where other bacteriological procedures are not available.

It scerns likely that viral infections of the lung are increasing, and viral cultures should be included in any future investigation.
\end{abstract}

Las neumopatias agudas constituyen una de las patologías más frecuentes de las unidades de lactantes de los hospitales de niños. Entre los problemas diagnósticos de mayor trascendencia práctica que ellos plantean, está su etiología, por las consecuencias terapéuticas que ello implica. Los gérmenes causantes de estas afecciones se han buscado en las vias respiratorias superiores, en la sangre y en el tejido pulmonar mismo. Desde hace años se ha establecido que la flora bacteriana y/o viral de las vias respiratorias altas no coincide con los agentes causales de las infecciones pulmonares.

Los intentos para obtener liquido pulmonar por punción han sido revisados por Hughes ${ }^{1}$. Otros autores $^{4}$ han preferido obtener muestras de secreción traqueal, ya sea mediante punción o por introducción de una sonda. Finalmente se ha estudiado también el rendimiento de los hemocultivos en estos enfermos.

El objeto de este trabajo ha sido evaluar el rendimiento del conjunto de estas diferentes técnicas en un grupo de lactantes hospitalizados con los diagnósticos de neumonia o bronconeumonia.

\section{MATERIAL Y METODO}

La investigación se efectuó en veinticuatro lactantes de uno a veintitrés meses de edad, ingresa-

1 Departamento de Pediatría de la Universidad Católica y Servicio de Pediatría del Hospital Dr. Sótero del Río. dos al Hospital de Niños Josefina Martínez Ferrari (HJMF) con el diagnóstico de neumopatia aguda, entre los años 1978-1980. En todos ellos se efectuó al ingreso un estudio radiológico de tórax, seleccionando para esta investigación todos aquellos que revelaron imágenes de condensación pulmonar. Se excluyó a los que presentaron signos de insuficiencia respiratoria, hiperinsuflación pulmonar exagerada o empiema pleural.

En cada lactante se efectuó de inmediato hemo. grama, velocidad de sedimentación (VHS) y tres hemocultivos. Se obtuvo, además, una muestra de secreción traqueal mediante sonda Nelaton esterilizada provocando tos, o mediante maniobras kinésicas. Finalmente se practicó en ellos una punción de pulmón de acuerdo a técnica clásical

El líquido obtenido, se sembró en una placa de agar sangre para estudio bacteriológico.

Como elementos clínicos indicadores de infección bacteriana se consideró una VHS de 30 o más $\mathrm{mm}$ en la primera hora y un Hermograma con tres o euatro parámetros alterados: leucocitos sobre $12.000 \times \mathrm{mm}^{3}$, porcentaje de polimorfonucleares mayor del $50 \%$, Granulaciones Tóxico-Degenerativas (GTD) en los neutrófilos con dos o tres cruces y número de baciliformes superior a $500 \mathrm{x}$ $\mathrm{mm}^{3}$.

\section{RESULTADOS}

El estudio incluyó 24 lactantes de los cuales $46 \%$ eran eutróficos y $29 \%$ presentaban desnutrición severa grados II o III. En once casos existían 
antecedentes de infecciones respiratorias anteriores y 10 habían recibido tratamiento antibjótico ambulatorio previo para su enfermedad actual.

Según los resultados del estudio radiológico nueve nifios tenían Neumonías lobares o segmen- tarias (N) y 15 Bronconeumonias (BNM).

Las características etarias, de estado nutritivo, diagnóstico radiológico pulmonar y resultados de cultivos se presentan en la Tabla 1.

Tabla 1.

Caracteristicas etarias, estado nutritivo, diagnóstico radiológico y resultados cultivo bacteriológico de 24 lactantes con neumopatía aguda. Hospital Josefina Martinez de Ferrari (1978-1980).

\begin{tabular}{|c|c|c|c|c|c|}
\hline $\begin{array}{l}\text { Edad } \\
(m)\end{array}$ & E. Nutticional & Diag. & $\begin{array}{l}\text { Resultados } \\
\text { Punción } \\
\text { Pulmonar }\end{array}$ & $\begin{array}{c}\text { Estudios } \\
\text { Hemocultivos }\end{array}$ & $\begin{array}{l}\text { Bacteriológico } \\
\text { Secreción traqueal }\end{array}$ \\
\hline $\begin{array}{r}9 \\
5 \\
6 \\
12 \\
23 \\
9\end{array}$ & $\begin{array}{l}\text { DCP I } \\
E \\
E \\
E \\
D C P I \\
E\end{array}$ & $\begin{array}{l}\text { N } \\
\text { BNM } \\
\text { BNM } \\
\text { BNM } \\
\text { N } \\
\text { BNM }\end{array}$ & $\begin{array}{l}(-) \\
(-) \\
(-) \\
(-) \\
(-) \\
(-)\end{array}$ & $\begin{array}{l}(-) \\
(-) \\
(-) \\
(-) \\
(-) \\
(-)\end{array}$ & $\begin{array}{l}\text { E. Coli. } \\
(-) \\
\text { Strep. Viridans. } \\
\text { E. Coli. } \\
\text { Neisseria Catarr. } \\
\text { Staph. aurcis., Neisseria } \\
\text { Cattarr., Strep. Viridans. }\end{array}$ \\
\hline 18 & $\mathrm{E}$ & $\mathrm{N}$ & $(-)$ & Strep. Pneumoniae & Strep. Pneumoniae \\
\hline 24 & DCP III & $\begin{array}{l}\text { BNM } \\
\text { BNM }\end{array}$ & $(-)$ & $(-)$ & $\begin{array}{l}\text { Neisseria Catarr, } \\
\text { Strep. viridans. }\end{array}$ \\
\hline 10 & DCP [I] & $N$ & $(-)$ & Citrobacter. & $(-)$ \\
\hline 13 & $\begin{array}{l}\text { DCP I! } \\
\text { DCP I }\end{array}$ & $\begin{array}{l}\mathrm{N} \\
\mathrm{BNM}\end{array}$ & $\begin{array}{l}(-) \\
(-)\end{array}$ & $\begin{array}{l}(-) \\
(-)\end{array}$ & $\begin{array}{l}\text { Neisseria Catarr., } \\
\text { Strep. B - homolítico. } \\
\text { No practicado. }\end{array}$ \\
\hline 17 & DCP II & BNM & $(-)$ & Staph. aureus. & E. Coli. \\
\hline 4 & $\mathbf{E}$ & BNM & Staph. Epidermis. & $(-\cdots)$ & $\begin{array}{l}\text { Neisseia Catarr., } \\
\text { Sirep. Viridans. }\end{array}$ \\
\hline 8 & DCP I & BNM & $(-)$ & $(-)$ & Strep. Pneumoniae \\
\hline 14 & DCP I & BNMI & Staph. Epidermis. & Staph. Epidermidis. & Staph. Epidermidis. \\
\hline 4 & DCP I & BNM & $(-)$ & $(-)$ & Citrobacter. \\
\hline 7 & DCP IJI & $\mathrm{N}$ & $(-)$ & $(-)$ & Neısseria Catarr. \\
\hline 7 & DCP II & $\mathbf{N}$ & Staph. Aureus. & $(-)$ & No practicado. \\
\hline 14 & DCP II & $\mathrm{N}$ & $(-)$ & $(-)$ & No practicado. \\
\hline 24 & $\mathrm{E}$ & BNM & $(-)$ & $(-)$ & Neisseria Catart. \\
\hline 16 & $\mathrm{E}$ & $N$ & $(-)$ & $(-)$ & No practicado. \\
\hline 10 & $\mathrm{E}$ & $\mathrm{BNM}$ & $(-)$ & $(-)$ & No practicado. \\
\hline 9 & E & BNM & $\begin{array}{c}\text { Strep. Pneumoniae, } \\
\text { Strep. viridans. }\end{array}$ & $(-)$ & No practicado. \\
\hline
\end{tabular}

Se observa que se obtuvo resultado positivo en las punciones pulmonares en 4 de los 24 enfermos. Separando este grupo según antecedentes de tratamiento antibiótico previo al ingreso, se obtuvo resultado positivo en $1 / 10$ de los tratados y $3 / 14$ de aquellos sin tratamiento. La secreción traqueal dio resultado bacteriológico positivo en 14 de los 18 niños en que se practicó $(78 \%)$ pero los gérme- 
nes encontrados fueron en su mayoria los que aparecen como flora habitual de las vías respiratorias superiores. Finalmente, de las 24 series de hemocultivos realizados, 4 revelaron la existencia de gémmenes patógenos.

Sólo en un enfermo se aisló el mismo germen en los 3 tipos de cultivo, que fue un estafilococo epidermidis. En un segundo caso se cultivó estrep. tococo neumoniae en sangre y secreción traqueal, pero no en pulmón.

Considerando en conjunto los resultados bacteriológicos de pulmón y sangre, se pudo determinar etiología en 7 de los 24 casos (29\%). No se consideraron en esto los resultados de secreción traqueal por corresponder la mayoría de los gérmenes a flora habitual.
Se comparó la positividad de los cultivos entre los lactantes con diagnóstico radiológico de neumonia vs BNM, sin encontrar diferencias significativas ( $33 \%$ de positividad en sangre y/o pulmón en neumonias y $27 \%$ en BNM),

Respecto a los exámenes hematológicos realizados al ingreso, hubo signos francos de infección bacteriana en sólo 4 Hemogramas. La VHS fue mayor de $30 \mathrm{~mm}$ en la primera hora en 16 niños $(67 \%)$. No se encontró diferencias significativas de estos exámenes entre los enfermos catalogados como BNM y neumonias. La comparación de estos parámetros hematológicos entre el grupo de 7 niños con etiología bacteriana comprobada y los 17 restantes sin comprobación se presenta en la Tabla 2.

Tabla 2.

Valores de hemogramas y VHS en 24 lactantes con neumopatía aguda, con y sin etiología bacteriana comprobada (H.J.M.F. 1978-80)

\begin{tabular}{lccccccccc}
\hline Edología & YHS & $>30 \mathrm{~mm}$ & Leucocitos & $>12.000$ & Bacil sobre 500 & $\%$ poli & $>50 \%$ \\
\hline Bacteriana & No & $\%$ & No & $\%$ & No & $\%$ & No & $\%$ \\
\hline Comprobada & 5 & 71 & 5 & 71 & 1 & 14 & 4 & 57 \\
\hline No comprobada & 11 & 69 & 4 & 25 & 6 & 35 & 11 & 65 \\
\hline TOTAL & 16 & 69.5 & 9 & 37.5 & 7 & 29.2 & 15 & 62.5 \\
\hline
\end{tabular}

Se observa que la proporción de casos con VHS sobre $30 \mathrm{~mm}$ en 1 hora es prácticamente igual en ambos grupos, en tanto que, de los 3 parámetros seleccionados del hemograma, la proporción con leucocitosis sobre 12.000 fue claramente más alta entre los enfermos con cultivos positivos de sangre y/o pulmón, siendo esta diferencia estadísticamente significativa.

\section{COMENTARIO:}

El conocimiento de la etiología de los procesos infecciosos agudos pulmonares continúa siendo impreciso, por las dificultades prácticas de obtener muestras bacteriológicas confiables del parénquima pulmonar. Diversos autores han demostrado la falta de coincidencia entre los gérmenes obtenidos de las secreciones del rinofarinx y tráquea con los causantes de la inflamación pulmonar. En nuestro estudio encontramos coincidencia bacteriológica en ambos sitios sólo en un niño, y las bacterias aisladas de la secreción traqueal correspondían en su mayoría a flora respiratoria alta habitual.

Algunos autores recomiendan mejorar el rendimiento del estudio bacteriológico de la secreción traqueal mediante la punción de este órgano, que daría mejor resultado que la pulmonar ${ }^{4}$. Nosotros intentamos previamente esta técnica en un lactanlte, pero desistimos de continuarla por parecernos excesivamente traumatizante a esta edad.

La positividad de $17 \%$ obtenida en esta investigación con la punción pulmonar parece bastante baja en relación con la literatura. Shuster ${ }^{2}$ obtuvo resultados positivos en el $54 \%$ de su material; Mimica $^{3}$ en el $45 \%$; Hughes ${ }^{1}$ refiere hallazgos positivos a bacterias o virus en 7 de 18 enfermos, el $39 \%$, y Klein ${ }^{9}$ en 10 de 28 , el 36\%. Este último autor resume los resultados de otras investigaciones, con porcentajes de positividad que varian entre 20 y $80 \%$. Además, el tipo de gérmenes aislados por nosotros difiese también de lo señalado en la literatura, en que las mayores frecuencias corresponden al Neumococo ${ }^{9}$ al Hemophilus influenzae ${ }^{1}$, ocupando, en general, el tercer lugar el estafilococo. En nuestro material, en cambio, se encontró este último germen en 3 de los 4 casos positivos, y en un solo paciente un neumococo, en combinación con un estreptococo viridans. De los 3 lactantes con cultivo positivo a estafilococo, sólo en un caso era del tipo aureus y en 2 epidermidis, que se considera generalmente como contaminante. Sin embargo, esta bacteria puede llegar a tener acción patógena en ciertas circunstancias. Estas disparidades podrian explicarse porque algunos de 
los niños estudiados habian recibido tratamiento antibiótico ambulatorio previo a su hospitalización. Shuster ${ }^{2}$ demostró que este antecedente no altera los resultados del examen y la diferencia de $1 / 10$ vs $3 / 14$ en nuestro estudio no es significativa Dado que la mayor parte de las investigaciones citadas en la literatura son anteriores a 1970 , es posible que se haya producido un cambio en la flora de las infecciones pulmonares, con mayor incidencia de la etiología viral, o bien que las. técnicas bacteriológicas de nuestro laboratorio hayan sido jnadecuadas.

En relación a la primera de estas hipótesis, Hughes ${ }^{1}$ ya en 1968 alertaba sobre la importancia creciente de los virus como agentes etiológicos de las neumopatías infecciosas. Entre nosotros, Cas. tro ${ }^{11}$ presentó en 1975 un caso anatomo-clínico de BNM bilateral, con extensas condensaciones y empiema pleural, $y$ de etiología muy probablemente viral. Nosotros no hemos tenido la posibilidad de efectuar estudio virológico en nuestros enfermos, y hemos tratado de orientarnos sobre esta etiología mediante el uso de parámetros indirectos, como el tipo de lesión radiológica, la VHS y el hemograma. No hemos utilizado, sin embargo, la proteína C-reactiva, que parece tener mayor valor que las anteriores.

Respecto a la baja positividad explicable por técnicas imperfectas de laboratorio, nosotros hemos usado las técnicas clásicas de estudio bacteriológico, pero probablemente el rendimiento habría mejorado si hubiéramos podido disponer de otras têcnicas más modernas y rápidas para identificación de gérmenes, como la inmuno-electroforesis de contracorriente, la aglutinación de latex, la inmunofluorescencia, cromatografía por gas, microscopía electrónica o el ELISA.

La positividad de los hemocultivos fue también baja $(17 \%)$, en concordancia con otras investigaciones nacionales ${ }^{12}$, pero el $29 \%$ de positividad bacteriológica obtenido, considerando en conjunto el cultivo de sangre y líquido pulmonar, podria justificar su uso en cuadros pulmonares del lactante, especialmente en aquellos resistentes a los antibióticos de primera línea.

Finalmente, el examen de secreciones extraídas con sonda de la tráquea no contribuyó mayormente en nuestro estudio a aclarar la etiología, de acuerdo con la opinión generalizada. El uso de punción traqueal no nos parece aplicable en el lactante.

Respecto al valor de la VHS y del hemograma como indicadores de infección bacteriana, ha aparecido abundante literatura en el último tiempo ${ }^{5-6-7-B}$ con resultados algo contradictorios.

En la experiencia actual, estos parámetros hematológicos no guardaron relación ni con el tipo de lesión (neumonia o BNM) ni con la comprobación de bacterjas en la sangre y/o pulmón. Sólo la leucocitosis sobre 12.000 se presentó en una proporción claramente más alta en los enfermos con cultivos positivos, diferencia que no aumentó al subir la exigencia a 15.000 leucocitos $\mathrm{mm}^{3}$.

Respecto a la técnica misma de punción pulmo. nar, ella es sencilla y no tuvimos ningún tipo de complicaciones, coincidiendo con lo expresado en la literatura ${ }^{1-2-9-10}$.

\section{RESUMEN Y CONCLUSIONES:}

Se practica estudio bacteriológico en sangre, secreción traqueal extraida por sonda y líquido pulmonar, obtenido por punción de este órgano, a 24 lactantes con diagnóstico de BNM o neumonia en el momento de su ingreso al hospital.

La punción pulmonar dio resultado positivo en 4 casos $(17 \%)$, correspondiendo en 3 a alguna forma de stafilococo y en 1 a una combinación de Streptoc. pneumoniae y viridans. La positividad de los hemocultivos se observó también en 4 casos (2 stafilococos, 1 citrobacter $y \cdot 1$ str. pneumoniae). Hubo sólo un enfermo oon coincidencia del germen en ambos sitios. Las secreciones de tráquea dieron resultados bacteriológicos positivos en el $78 \%$ de los casos $(14 / 18)$, pero este resultado carece de importancia, por ser la mayoria gérmenes de la flora respiratoria alta habitual.

Ni las alteraciones de la VHS ni de diferentes parámetros del Hemograma mostraron correlación con el hallazgo de gérmenes en sangre o pulmón, excepto un recuento de leucocitos superior a 12.000 , que se observó en una proporción significativamente más alta en los lactantes con etiología bacteriana comprobada.

No se presentaron complicaciones derivadas de la punción pulmonar y su ejecución fue sencilla.

Pese al escaso rendimiento del hemocultivo $y$ punción pulmonar en forma aislada, y a la baja concordancia entre los resultados de ambos, el porcentaje de $29 \%(7 / 24)$ de cultivos positivos sangre y/o pulmón combinados, justificaria su realización en algunos enfermos, especialmente aquellos resistentes al tratamiento corriente. El recuento de leucocitos sería un elemento útil en este sentido.

Debido al aparente aumento de las infecciones pulmonares producidas por virus, su estudio deberia incluirse también en los casos de neumopatías agudas đe evolución anormal.

\section{REFERENCIAS}

${ }^{1}$ Hugues $J$. et al.: “Lung tap in childhood". Ped. 44, 4: 477,1969 . 
${ }^{2}$ Schuster A. et al::"La punción biopsia pulmonar como método diagnóstico de las neumopatías en la infan. cia". Pediatría 9: 9, 1966.

3 Mimica I.; Donoso E.; Howard J.; Ledermann W.: "Lung Puncture in etiologic diagnosis of pneumonie: Study of 543 infants and children". Am. J. Dis. Child. 122: $278-282,1971$.

4 Brook f. and Fitzgerald, SM: "Bacteriology' of aspiration pneumonie in children" Ped. 65, 6: 1115, 1980.

5 Tolesnik E, et al.: "Estudio hematológico en Septicemias bactcrianas del lactante". Rev. Chil. Ped. 48, 3-4: 120, 1977.

6 Mc Carthy PL, Jekel JF.; Dolan TF JR.; "Tenperature greater than or cqual to $40^{\circ} \mathrm{C}$ in children less than 24 months of age". Ped. 59, 663, 1977.
${ }^{7}$ MC Carthy PL.: Jekel JF and Dolan FF.: "Comparison of acute-phase reactaris in pediatric patients with fever". Ped. 62.5: 716, 1978.

${ }^{8}$ Baron MA and FINK MD.: "Bacteremia in private pediatric practice". Ped. 66.2: 171, 1980.

"Jerome, K.: "Diaglostic Lung puncture in the pneumonies of infants and childsen". Ped. 44: 486 , 1969.

10 Finland, M.: "Diagnostic Lung puncture". Ped, 44: $471,1969$.

11 Castro M.; Mirking D.; Avendaño LF.: "Reunión Anatomoclínica". Ped. 19.1: 77, 1976.

12 Herrera Pet ol: "Hemocultivo en neumopatías agudas del niño menor". Ped. 2112: 128, 1978. 